\title{
Emerging interactions between matrix components during biofilm development
}

\author{
David E. Payne ${ }^{1} \cdot$ Blaise R. Boles ${ }^{1}$
}

Received: 9 October 2015 / Revised: 13 October 2015 / Accepted: 14 October 2015 / Published online: 29 October 2015

(C) The Author(s) 2015. This article is published with open access at Springerlink.com

\begin{abstract}
Bacterial cells are most often found in the form of multicellular aggregates commonly referred to as biofilms. Biofilms offer their member cells several benefits, such as resistance to killing by antimicrobials and predation. During biofilm formation there is a production of extracellular substances that, upon assembly, constitute an extracellular matrix. The ability to generate a matrix encasing the microbial cells is a common feature of biofilms, but there is diversity in matrix composition and in interaction between matrix components. The different components of bacterial biofilm extracellular matrixes, known as matrix interactions, and resulting implications are discussed in this review.
\end{abstract}

Keywords Staphylococcus aureus · Functional amyloids $\cdot$ Biofilm $\cdot$ eDNA $\cdot$ Polysaccharide

\section{Biofilms and their matrix}

A common strategy employed by bacteria to survive in varied environmental conditions is to develop into an encased community of cells called biofilm. The fact that these multicellular communities can grow on surfaces with diverse chemistries, persist in hostile environments, and resist clearance by strategies that typically eradicate planktonic bacteria is a topic of much interest to researchers from

Communicated by M. Kupiec.

Blaise R. Boles

blaise-boles@uiowa.edu

1 Department of Microbiology, Roy J. and Lucille A. Carver College of Medicine, University of Iowa, Iowa City, IA, USA diverse disciplines. It is clearly evident that many pathogenic bacteria use the biofilm growth mode to persist in the host and avoid clearance by the immune system and antimicrobial chemotherapies leading to the development of persistent infections (Costerton et al. 1999; Mathe and Van Dijck 2013; Parsek and Singh 2003). The increasing use of implant materials in healthcare settings further exacerbates this problem as foreign bodies are known to promote the initiation of biofilms (Thurlow et al. 2011; Zimmerli et al. 2004).

A major area of interest in biofilm research is the composition of the substances holding these communities of cells together. This polymeric material is usually referred to as the "biofilm matrix." The exact composition, potential interactions, and the role of the different matrix components are not fully understood. There is considerable interest in gaining an improved understanding of the biofilm matrix because bacteria with matrix defects are often unable to form a biofilm and treatments that breakdown the matrix transition cells to an antimicrobial susceptible state (Boles and Horswill 2008, 2011; Lauderdale et al. 2010; Payne et al. 2013). The exact composition of the biofilm matrix can vary greatly between different bacterial species, strains, and growth conditions, therefore, it should be noted that not all biofilms are equivalent and variation has routinely been observed between strains of the same species.

In the case of Staphylococcus species, including $S$. aureus, the primary matrix components consist of polysaccharides (Cramton et al. 1999), proteins (Beenken et al. 2010; Cramton et al. 1999; Lauderdale et al. 2010; Marti et al. 2010; O'Neill et al. 2008; Tsang et al. 2008), and extracellular DNA (eDNA) (Izano et al. 2008; Kaplan et al. 2012) (Fig. 1). Though not commonly appreciated as matrix components, extracellular teichoic acids have been purified from the matrix material of Staphylococcal 




Fig. 1 Confocal micrograph of a Staphylococcus aureus biofilm growing on a catheter. The biofilm was stained with two DNA strains, syto-9 (green) and draq-5 (blue). Green cocci are S. aureus cells encased in a blue matrix that consists part of eDNA

biofilms (Chaignon et al. 2007) and peptidoglycan has been proposed to play an unidentified role in the matrix based on observations that exposure to lysostaphin, an enzyme capable of degrading the pentaglycine bridge in the staphylococcal cell wall, can successfully detach biofilms (Kokai-Kun et al. 2009). In addition, host factors are likely to be incorporated into the biofilm matrix but this is largely unstudied and likely varies depending upon infection site. Below, we attempt to summarize much of what is known about these matrix components and their potential interactions.

\section{Polysaccharide}

Many Staphylococcal species produce a poly- $N$-acetyl glucosamine (PNAG) polysaccharide, which is also referred to as polysaccharide intercellular adhesin (PIA). PNAG is synthesized by enzymes encoded by the ica operon and deposited on the cell wall surface (Cramton et al. 1999). Many environmental growth conditions likely contribute to the role of PNAG in the Staphylococcus biofilm matrix. These include anaerobic growth, high temperatures, osmolarity, and other environmental stresses including the presence of sub-inhibitory concentrations of antibiotics (O'Gara 2007). In some animal models of Staphylococcal biofilm infections, PNAG has been shown to play a crucial role in establishing a biofilm and maintaining a persistent infection (Rupp et al. 1999a, b, 2001). Because of this role in pathogenesis, efforts have been made to utilize PNAG as a vaccine candidate and have been met with mixed results. More recent evidence suggests that while some Staphylococcal strains rely on polysaccharides for robust biofilm formation, others form polysaccharide-independent biofilms (Boles et al. 2010; Izano et al. 2008; O'Gara 2007; Rohde et al. 2007). In cases of polysaccharide-independent biofilm formation, proteins and eDNA most likely substitute for PNAG as a structural matrix component.

\section{Proteins}

Proteins are another major biofilm matrix component, as evidenced by the susceptibility of staphylococcal biofilms to proteases (Beenken et al. 2010; Boles and Horswill 2008; Marti et al. 2010). Many cell-cell and cell-host tissue contacts within a biofilm are mediated by surface proteins. Some surface proteins, such as the fibronectin binding proteins (O'Neill et al. 2008), protein A (Merino et al. 2009), SasG (Conrady et al. 2008, Corrigan et al. 2007), and biofilm associated protein (BAP) (Trotonda et al. 2005), have been defined as being important in cell-cell and cell-surface interactions occurring during biofilm development. It has also been suggested that cytoplasmic proteins play a moonlighting role in the matrix where they associate with cells upon a drop in pH (Ebner et al. 2015; Foulston et al. 2014). In addition, amyloids have recently emerged as an important proteinaceous component of many microbial biofilms, including $S$. aureus. First identified in human neurodegenerative diseases, amyloids are insoluble fibrous aggregates of proteins that contain parallel beta sheets. The amyloid fibers produced by $S$. aureus are composed of small peptides called phenol-soluble modulins (PSMs) (Schwartz et al. 2010, 2012, 2014). Amyloids are notorious for being relatively resistant to protease digestion and insoluble in detergents. Therefore, in the biofilm environment, these amyloids offer resistance to proteases and surfactants capable of degrading biofilms.

\section{eDNA}

Extracellular genomic DNA (eDNA) is thought to be an important structural component in many bacterial biofilms including those formed by S. aureus (Okshevsky and Meyer 2014, 2015; Vorkapic et al. 2015). The addition of DNase to growing or mature biofilms of various bacterial species results in inhibition of biofilm formation or disruption of the established biofilms. However, DNase-mediated disruption of established biofilms is dependent upon biofilm age with "young" biofilms being more sensitive than "old" 
biofilms. In $S$. aureus, autolytic activity from a subpopulation of cells results in the release of genomic DNA that contributes to cell adhesion during biofilm maturation (Qin et al. 2007). The chemical nature of the long charged DNA molecule is thought to modulate the cell surface properties and to promote cell-to-cell and cell-to-surface adhesion and to serve a structural role in the $S$. aureus biofilm matrix (Mann et al. 2009; Rice et al. 2007).

\section{Matrix interactions}

Several recent studies have emerged, suggesting that matrix components are capable of interacting and influencing biofilm development. Structural analysis revealed that the secreted $S$. aureus protein beta toxin has a three-dimensional structure that resembles nuclease. Although it lacks nuclease activity, it is capable of binding to eDNA, and oligomerizing to form higher ordered states. The beta toxineDNA interconnection acts as a skeletal framework of the biofilm that is critical for the biofilm matrix during infection (Huseby et al. 2010). The fact that many clinical isolates possess a phage interrupting the beta toxin gene has lead to the thought that this protein is not relevant to infection in those strains and there may be other eDNA-binding proteins that await identification. However, this notion has recently been challenged by work showing phage excision can occur during infection resulting in active beta toxin production (Salgado-Pabon et al. 2014).

Cytoplasmic proteins presumably released via autolysis have also recently been shown to interact with eDNA in a $\mathrm{pH}$-dependent manner and this inaction offers protection from matrix degrading enzymes (Dengler et al. 2015). This work suggests that rather than dedicated proteins being made to contribute to the biofilm matrix, cytoplasmic proteins may "moonlight" in the matrix environment offering interactions between eDNA and cell wall material. Indeed, in gram-negative pathogens such as Haemophilus influenza and Burkholderia cenocepacia, proteins such as the integration host factor (IHF) protein have been shown to interact with eDNA and stabilize biofilms. Attempts to remove these proteins from biofilms using antisera that block protein-DNA interactions have shown promise at reducing biofilm biomass in vitro and treating chronic infections in animal models (Goodman et al. 2011; Jurcisek and Bakaletz 2007; Novotny et al. 2013). Considering that IHF is a member of the DNABII protein family that includes nucleoid-associated proteins like $\mathrm{HU}$, which are present in both gram-negative and gram-positive pathogens, this strategy may hold promise at reducing biofilms against a variety of bacterial species. Recent work in S. aureus has also suggested that proteins typically thought of as being cytoplasmic could have a role in the biofilm matrix (Dengler et al.
2015; Foulston et al. 2014). The authors found the association of eDNA with the biofilm matrix was dependent on matrix proteins, some of which seem to have a moonlighting role in the matrix, as they are cytoplasmic proteins only released from the cell upon autolysis (Dengler et al. 2015). The addition of eDNA to DNase-treated cells could rescue biofilm formation/clumping suggesting a role for eDNA in facilitating cell-to-cell interactions.

Amyloids have also been shown to interact with other matrix components in the biofilm matrixes of $S$. aureus and E. coli (DePas and Chapman 2012). In the case of $S$. aureus, it was found that the presence of eDNA promotes the polymerization of amyloidogenic peptides (phenol -soluble modulins (PSM)) at concentrations that PSMs alone do not readily polymerize (Schwartz et al. 2015). It is suggested that this is a result of DNA attracting the positively charged PSMs and raising the local peptide concentration, therefore resulting in polymerization. In E. coli the functional amyloid component, $\mathrm{Csg} \mathrm{A}$ has been shown to bind to DNA, promoting curli amyloid assembly (Fernandez-Tresguerres et al. 2010) and the resulting DNA/amyloid complex acts to stimulate autoimmunity (Gallo et al. 2015).

Interactions between eDNA and polysaccharides have also been observed in biofilms. In P. aeruginosa, two main biofilm matrix components (eDNA and the polysaccharide Psl) cooperate by physically interacting in a biofilm to form the web of Psl-eDNA fibers, which functions as a skeleton to allow bacteria to adhere and grow (Wang et al. 2015). Psl can interact not only with DNA of P.aeruginosa, but also the genomic DNA from human neutrophils and $S$. aureus, implying that P.aeruginosa has the ability to use DNA of other organisms to form its own communities.

\section{Outlook}

Despite the importance of microbial biofilms to human health and industrial processes interactions between biofilm matrix components, remain poorly defined. Emerging work discussed above is demonstrating several matrix interactions (eDNA-protein, eDNA-amyloid and eDNApolysaccharide) and there is little doubt that more interactions between matrix components and the mechanism underlying these interactions await to be elucidated. Interactions between matrix components within the biofilm are likely responsible for creating an adaptable structure during adherence, maturation, and dispersal. These findings underscore the notion that the formation of biofilm matrix is a complex, dynamic process with contribution of multiple factors, including bacterial cell death, the release of eDNA, the secretion of protein and the interaction between the matrix components. 
In future work, it will be of interest to understand how host factors may be incorporated into bacterial biofilm matrixes and how these potential interactions may influence biofilm development. Considering that the negatively charged polymer DNA is central to most known matrix interactions, it is tempting to speculate that negatively charged host polymers such as hyaluronic acid and heparin could play a similar role. Biofilm matrix interactions may also provide novel targets for disrupting biofilm formation and eradicating established biofilms. Considering the dire health consequences many biofilm infections impose, this should be an area of emerging interest.

Open Access This article is distributed under the terms of the Creative Commons Attribution 4.0 International License (http://creativecommons.org/licenses/by/4.0/), which permits unrestricted use, distribution, and reproduction in any medium, provided you give appropriate credit to the original author(s) and the source, provide a link to the Creative Commons license, and indicate if changes were made.

\section{References}

Beenken KE, Mrak LN, Griffin LM, Zielinska AK, Shaw LN, Rice KC, Horswill AR, Bayles KW, Smeltzer MS (2010) Epistatic relationships between sarA and agr in Staphylococcus aureus biofilm formation. PloS one 5:e10790. doi:10.1371/journal. pone. 0010790

Boles BR, Horswill AR (2008) Agr-mediated dispersal of Staphylococcus aureus biofilms. PLoS Pathogens 4:e1000052. doi:10.1371/journal.ppat.1000052

Boles BR, Horswill AR (2011) Staphylococcal biofilm disassembly. Trends Microbiol 19:449-455. doi:10.1016/j.tim.2011.06.004

Boles BR, Thoendel M, Roth AJ, Horswill AR (2010) Identification of genes involved in polysaccharide-independent Staphylococcus aureus biofilm formation. PloS One 5:e10146. doi:10.1371/journal.pone.0010146

Chaignon P, Sadovskaya I, Ragunah C, Ramasubbu N, Kaplan JB, Jabbouri S (2007) Susceptibility of staphylococcal biofilms to enzymatic treatments depends on their chemical composition. Appl Microbiol Biotechnol 75:125-132. doi:10.1007/ s00253-006-0790-y

Conrady DG, Brescia CC, Horii K, Weiss AA, Hassett DJ, Herr AB (2008) A zinc-dependent adhesion module is responsible for intercellular adhesion in staphylococcal biofilms. Proc Natl Acad Sci USA 105:19456-19461. doi:10.1073/pnas.0807717105

Corrigan RM, Rigby D, Handley P, Foster TJ (2007) The role of Staphylococcus aureus surface protein SasG in adherence and biofilm formation. Microbiology 153:2435-2446. doi:10.1099/ mic. $0.2007 / 006676-0$

Costerton JW, Stewart PS, Greenberg EP (1999) Bacterial biofilms: a common cause of persistent infections. Science (New York, NY) 284:1318-1322

Cramton SE, Gerke C, Schnell NF, Nichols WW, Gotz F (1999) The intercellular adhesion (ica) locus is present in Staphylococcus aureus and is required for biofilm formation. Infect Immun 67:5427-5433

Dengler V, Foulston L, DeFrancesco AS, Losick R (2015) An electrostatic net model for the role of extracellular DNA in biofilm formation by Staphylococcus aureus. J Bacteriol. doi:10.1128/ jb.00726-15
DePas WH, Chapman MR (2012) Microbial manipulation of the amyloid fold. Res Microbiol 163:592-606. doi:10.1016/j. resmic.2012.10.009

Ebner P, Rinker J, Gotz F (2015) Excretion of cytoplasmic proteins in Staphylococcus is most likely not due to cell lysis. Curr Genet. doi:10.1007/s00294-015-0504-Z

Fernandez-Tresguerres ME, de la Espina SM, Gasset-Rosa F, Giraldo R (2010) A DNA-promoted amyloid proteinopathy in Escherichia coli. Mol Microbiol 77:1456-1469. doi:10.1111/j.1365-2958.2010.07299.x

Foulston L, Elsholz AK, DeFrancesco AS, Losick R (2014) The extracellular matrix of Staphylococcus aureus biofilms comprises cytoplasmic proteins that associate with the cell surface in response to decreasing $\mathrm{pH}$. mBio 5: e01667-01614. doi:10.1128/mBio.01667-14

Gallo PM, Rapsinski GJ, Wilson RP, Oppong GO, Sriram U, Goulian M, Buttaro B, Caricchio R, Gallucci S, Tukel C (2015) AmyloidDNA composites of bacterial biofilms stimulate autoimmunity. Immunity 42:1171-1184. doi:10.1016/j.immuni.2015.06.002

Goodman SD, Obergfell KP, Jurcisek JA, Novotny LA, Downey JS, Ayala EA, Tjokro N, Li B, Justice SS, Bakaletz LO (2011) Biofilms can be dispersed by focusing the immune system on a common family of bacterial nucleoid-associated proteins. Mucosal Immunol 4:625-637. doi:10.1038/mi.2011.27

Huseby MJ, Kruse AC, Digre J, Kohler PL, Vocke JA, Mann EE, Bayles KW, Bohach GA, Schlievert PM, Ohlendorf DH, Earhart CA (2010) Beta toxin catalyzes formation of nucleoprotein matrix in staphylococcal biofilms. Proc Natl Acad Sci USA 107:1440714412. doi:10.1073/pnas.0911032107

Izano EA, Amarante MA, Kher WB, Kaplan JB (2008) Differential roles of poly-N-acetylglucosamine surface polysaccharide and extracellular DNA in Staphylococcus aureus and Staphylococcus epidermidis biofilms. Appl Environ Microbiol 74:470-476. doi:10.1128/aem.02073-07

Jurcisek JA, Bakaletz LO (2007) Biofilms formed by nontypeable Haemophilus influenzae in vivo contain both double-stranded DNA and type IV pilin protein. J Bacteriol 189:3868-3875. doi:10.1128/jb.01935-06

Kaplan JB, Izano EA, Gopal P, Karwacki MT, Kim S, Bose JL, Bayles KW, Horswill AR (2012) Low levels of beta-lactam antibiotics induce extracellular DNA release and biofilm formation in Staphylococcus aureus. mBio 3:e00198-00112. doi:10.1128/ mBio.00198-12

Kokai-Kun JF, Chanturiya T, Mond JJ (2009) Lysostaphin eradicates established Staphylococcus aureus biofilms in jugular vein catheterized mice. J Antimicrob Chemother 64:94-100. doi:10.1093/ $\mathrm{jac} / \mathrm{dkp} 145$

Lauderdale KJ, Malone CL, Boles BR, Morcuende J, Horswill AR (2010) Biofilm dispersal of community-associated methicillinresistant Staphylococcus aureus on orthopedic implant material. J Orthopaed Res 28:55-61. doi:10.1002/jor.20943

Mann EE, Rice KC, Boles BR, Endres JL, Ranjit D, Chandramohan L, Tsang LH, Smeltzer MS, Horswill AR, Bayles KW (2009) Modulation of eDNA release and degradation affects Staphylococcus aureus biofilm maturation. PloS One 4:e5822. doi:10.1371/journal.pone.0005822

Marti M, Trotonda MP, Tormo-Mas MA, Vergara-Irigaray M, Cheung AL, Lasa I, Penades JR (2010) Extracellular proteases inhibit protein-dependent biofilm formation in Staphylococcus aureus. Microbes Infect 12:55-64. doi:10.1016/j.micinf.2009.10.005

Mathe L, Van Dijck P (2013) Recent insights into Candida albicans biofilm resistance mechanisms. Curr Genet 59:251-264. doi:10.1007/s00294-013-0400-3

Merino N, Toledo-Arana A, Vergara-Irigaray M, Valle J, Solano C, Calvo E, Lopez JA, Foster TJ, Penades JR, Lasa I (2009) Protein A-mediated multicellular behavior in Staphylococcus aureus. J Bacteriol 191:832-843. doi:10.1128/jb.01222-08 
Novotny LA, Amer AO, Brockson ME, Goodman SD, Bakaletz LO (2013) Structural stability of Burkholderia cenocepacia biofilms is reliant on eDNA structure and presence of a bacterial nucleic acid binding protein. PloS One 8:e67629. doi:10.1371/journal. pone.0067629

O'Gara JP (2007) ica and beyond: biofilm mechanisms and regulation in Staphylococcus epidermidis and Staphylococcus aureus. FEMS Microbiol Lett 270:179-188. doi:10.1111/j.1574-6968.2007.00688.x

Okshevsky M, Meyer RL (2014) Evaluation of fluorescent stains for visualizing extracellular DNA in biofilms. J Microbiol Methods 105:102-104. doi:10.1016/j.mimet.2014.07.010

Okshevsky M, Meyer RL (2015) The role of extracellular DNA in the establishment, maintenance and perpetuation of bacterial biofilms. Crit Rev Microbiol 41:341-352. doi:10.3109/10408 41x.2013.841639

O'Neill E, Pozzi C, Houston P, Humphreys H, Robinson DA, Loughman A, Foster TJ, O'Gara JP (2008) A novel Staphylococcus aureus biofilm phenotype mediated by the fibronectin-binding proteins, FnBPA and FnBPB. J Bacteriol 190:3835-3850. doi:10.1128/jb.00167-08

Parsek MR, Singh PK (2003) Bacterial biofilms: an emerging link to disease pathogenesis. Annu Rev Microbiol 57:677-701. doi:10.1146/annurev.micro.57.030502.090720

Payne DE, Martin NR, Parzych KR, Rickard AH, Underwood A, Boles BR (2013) Tannic acid inhibits Staphylococcus aureus surface colonization in an IsaA-dependent manner. Infect Immun 81:496-504. doi:10.1128/IAI.00877-12

Qin Z, Ou Y, Yang L, Zhu Y, Tolker-Nielsen T, Molin S, Qu D (2007) Role of autolysin-mediated DNA release in biofilm formation of Staphylococcus epidermidis. Microbiology 153:2083-2092. doi:10.1099/mic.0.2007/006031-0

Rice KC, Mann EE, Endres JL, Weiss EC, Cassat JE, Smeltzer MS, Bayles KW (2007) The cidA murein hydrolase regulator contributes to DNA release and biofilm development in Staphylococcus aureus. Proc Natl Acad Sci USA 104:8113-8118. doi:10.1073/ pnas.0610226104

Rohde H, Burandt EC, Siemssen N, Frommelt L, Burdelski C, Wurster S, Scherpe S, Davies AP, Harris LG, Horstkotte MA, Knobloch JK, Ragunath C, Kaplan JB, Mack D (2007) Polysaccharide intercellular adhesin or protein factors in biofilm accumulation of Staphylococcus epidermidis and Staphylococcus aureus isolated from prosthetic hip and knee joint infections. Biomaterials 28:1711-1720. doi:10.1016/j.biomaterials.2006.11.046

Rupp ME, Ulphani JS, Fey PD, Bartscht K, Mack D (1999a) Characterization of the importance of polysaccharide intercellular adhesin/hemagglutinin of Staphylococcus epidermidis in the pathogenesis of biomaterial-based infection in a mouse foreign body infection model. Infect Immun 67:2627-2632

Rupp ME, Ulphani JS, Fey PD, Mack D (1999b) Characterization of Staphylococcus epidermidis polysaccharide intercellular adhesin/hemagglutinin in the pathogenesis of intravascular catheter-associated infection in a rat model. Infect Immun 67:2656-2659

Rupp ME, Fey PD, Heilmann C, Gotz F (2001) Characterization of the importance of Staphylococcus epidermidis autolysin and polysaccharide intercellular adhesin in the pathogenesis of intravascular catheter-associated infection in a rat model. J Infect Dis 183:1038-1042. doi:10.1086/319279

Salgado-Pabon W, Herrera A, Vu BG, Stach CS, Merriman JA, Spaulding AR, Schlievert PM (2014) Staphylococcus aureus beta-toxin production is common in strains with the beta-toxin gene inactivated by bacteriophage. J Infect Dis 210:784-792. doi:10.1093/infdis/jiu146

Schwartz K, Stephenson R, Hernandez M, Jambang N, Boles BR (2010) The use of drip flow and rotating disk reactors for Staphylococcus aureus biofilm analysis. JoVE. doi:10.3791/2470

Schwartz K, Syed AK, Stephenson RE, Rickard AH, Boles BR (2012) Functional amyloids composed of phenol soluble modulins stabilize Staphylococcus aureus biofilms. PLoS Pathog 8:e1002744. doi:10.1371/journal.ppat.1002744

Schwartz K, Sekedat MD, Syed AK, O'Hara B, Payne DE, Lamb A, Boles BR (2014) The AgrD N-terminal leader peptide of Staphylococcus aureus has cytolytic and amyloidogenic properties. Infect Immun 82:3837-3844. doi:10.1128/IAI.02111-14

Schwartz K, Ganesan M, Payne DE, Solomon MJ, Boles BR (2015) Extracellular DNA facilitates the formation of functional amyloids in Staphylococcus aureus biofilms. Mol Microbiol. doi:10.1111/mmi.13219

Thurlow LR, Hanke ML, Fritz T, Angle A, Aldrich A, Williams SH, Engebretsen IL, Bayles KW, Horswill AR, Kielian T (2011) Staphylococcus aureus biofilms prevent macrophage phagocytosis and attenuate inflammation in vivo. J Immunol 186:65856596. doi:10.4049/jimmunol.1002794

Trotonda MP, Manna AC, Cheung AL, Lasa I, Penades JR (2005) SarA positively controls bap-dependent biofilm formation in Staphylococcus aureus. J Bacteriol 187:5790-5798. doi:10.1128/ jb.187.16.5790-5798.2005

Tsang LH, Cassat JE, Shaw LN, Beenken KE, Smeltzer MS (2008) Factors contributing to the biofilm-deficient phenotype of Staphylococcus aureus sarA mutants. PloS One 3:e3361. doi:10.1371/ journal.pone.0003361

Vorkapic D, Pressler K, Schild S (2015) Multifaceted roles of extracellular DNA in bacterial physiology. Curr Genet. doi:10.1007/ s00294-015-0514-x

Wang S, Liu X, Liu H, Zhang L, Guo Y, Yu S, Wozniak DJ, Ma LZ (2015) The exopolysaccharide Psl-eDNA interaction enables the formation of a biofilm skeleton in Pseudomonas aeruginosa. Environ Microbiol Rep 7:330-340. doi:10.1111/1758-2229.12252

Zimmerli W, Trampuz A, Ochsner PE (2004) Prosthetic-joint infections. N Engl J Med 351:1645-1654. doi:10.1056/ NEJMra040181 